\title{
Discurso Turístico e Internet, edited by Julia Sanmartín Sáez. Madrid: Lingüística Iberoamericana Vervuert, 2012.286 p.
}

\author{
Reviewed by María de la O Hernández-López \\ Pablo de Olavide University
}

We are living an age of globalization in which economic and technological barriers to world tourism continue to fall, at the same time that economic pressures rely more and more on international business, online resources and tourism. In this context, the impact of the Internet on the flows of outbound and inbound tourism is thriving as never before. Society now is living faster than ever, with constant emergent needs that need to be covered in order to ensure the expected quality of tourism services. Online communication has also proved to be a dynamic aspect of all national and international economy. It is fortunate that there is now a volume, Discurso Turistico e Internet (Tourism Discourse and Internet) that offers a global perspective on discursive specificities of those cybergenres associated to the tourism industry.

Discurso Turístico e Internet is designed to appeal not only scholars working in the field of Linguistics and Discourse Analysis, but also professionals in the Tourism Industry, University students and a more general audience interested in this specific topic. The authors have strong practical and conceptual backgrounds on language and communication, which are of paramount importance in the tourism industry and the Internet. Although the authors have worked independently to develop a series of chapters revolving around the same interest, all of them belong to IULMA (Instituto Interuniversitario de Lenguas Modernas Aplicadas) and have been in charge, since 2009, of examining a common corpus, COMET.VAL, including a set of texts of very varied nature within the tourism sector.

It is worth noting that while each chapter presents a different perspective, this volume also needs to be read as a unitary contribution with common features between chapters. Specifically, the methodology is mainly based on the use of tools such as AntConc and WordSmith 3.2, which allow for distribution analysis and lexical frequency, and therefore greatly facilitate the analysis of large amounts of texts. Another common feature of these nine chapters is the particular (but not exclusive) interest in the description, classification and interpretation of lexicon and terminology. Thus, the pillars of the lexicon will take the reader to discover applications in critical discourse analysis, terminology, pragmatics and translation in a carefully organized and thought-out manner.

As could not have been otherwise, Virginia González García introduces the book with a detailed classification of the existing cybergenres in relation to tourism, namely, institutional websites to promote tourism with the aim of promoting a tourist destination; commercial websites aiming at selling a particular destination, a flight or accommodation, among others; tourism Weblogs, either personal or corporate; social networks such as Facebook and Twitter; and finally travel Wikis such as Second Life. The author not only focuses on discursive and linguistic features but also demonstrates that the websites' versatility, hypertextuality, interactivity and upgradeability allow users to be active participants in the provision and reception of tourism information. Somehow, it is the democratization of information, by means of which users can gather information about specific destinations not only through commercial and institutional means, but also through other users, which range from the 
amateur level knowledge to a high degree of specialization. It is a useful chapter that introduces the rest of the book masterfully.

The next four chapters are based on a corpus of websites of various kinds. In Chapter 2 , for instance, Nuria Edo Marzá presents a study and classification of the use of adjectives in tourism promotion websites in English and Spanish. While no cross-linguistic variation was found, there is indeed a limited number of qualifiers in the digital medium that is intrinsic of tourism promotion. With a very personal organization, the author leads the reader from a general introduction of the tourism industry to the specification of linguistic studies and the importance of adjectives in tourism promotion websites. This chapter clearly lays the foundations to further explore this area of research in future studies.

Chapter 3 is a well-researched study of lexical and pragmatic hotel names and terminology in three regions (Galicia, Andalusia and Valencia) from both a normative and a user's perspective on tourism websites. In particular, Julia Sáez Sanmartín skilfully shows that while the current Spanish legislation includes a recognisable and closed-ended set of terms, tourism promotion websites are packed with either local terms (e.g., pazo or 'manor house' in Galicia) to make the accommodation unique, or new expressions with the form of collocations (e.g., hoteles con encanto or 'charming hotels' for couples) to attract a certain type of audience. This, however, may entail some ambiguity and difficulty when tourists search specific keywords on the website. On the other hand, if these terms do not conform to current regulations, there is the added problem of not having a reference to know exactly what features are included in the hotel of interest.

Chapter 4 turns to a more interpretative and analytical perspective by offering not only a study of the lexicon of websites to promote tourism, but also an interpersonal metadiscoursive perspective. Francisca Jimenez Sau examines the strategies of persuasion in tourism promotion websites in Spanish and English. The results show that, while in English the metadiscourse of persuasion is constructed through hedges, engagement markers, boosters and self-mentions, Spanish makes greater use of boosters, self-mentions and attitude markers. Thus, we can see that hedges and engagement markers are typical in (at least some) English persuasive contexts. In contrast, attitude markers are the most common feature in Spanish. These results indicate not only clear variation in terms of persuasive strategies to reach online users, butalso cultural differences in terms communication preferences. Considering this, no one would deny the indisputable application of this chapter to cross-cultural communication management, translation studies, stylistics and discourse studies, let alone the application that tourism professionals and marketing may find.

In Chapter 5, Rosana Dolón Herrero introduces, from a critical discourse analysis perspective, an aspect of great originality: the projection of the child's identity in discursive aspects of tourism promotion websites. After a solid and comprehensive introduction to the discursive construction of identity and a thorough explanation of the theoretical basis on which the study is based, the author denounces the indirect imposition on the child tastes and preferences in tourism websites, mainly regarding entertainment, outdoor activities and places to visit. According to the author, the contents related to children in tourism websites reveal that some activities are shown as dispreferred, such as visiting parks (which is obviously a 
cheap activity and therefore not convenient for marketers). The construction of children's identity, and therefore the creation of their needs by advertisers, not by themselves, are created and projected for travellers and parents by means of a particular lexicon, which is anything but fortuitous. Indeed, the marketers' tone, at times patronizing, at times colloquial, addresses parents' needs and fears to unilaterally build the supposed child's needs that eventually go without being questioned.

The volume takes a turn with Mary Estornell Pons in chapter 6, in which online travel and tourism magazines are examined considering two particular lexical phenomena: on the one hand, English loans or borrowings to refer to news services in the tourism sector, such as late check out; on the other, neologisms, i.e., expressions that designate existing activities but reformulated with new terminology to add creativity and expressiveness to the speech. Some examples would be citybreak, slow food or gayfriendly. These terms could be interpreted as having a twofold function in magazines: first, to designate and include new services that may be attractive to the reader and second, to add pragmatic expressiveness, novelty and style to the text. Meanings are not always clear, but these in turn provide the text with a wide range of connotations and nuances which may ultimately be attractive and saleable.

The most interactive cybergenres are introduced in chapters 7 and 8 . In particular, the travel Weblog and the forum are the focus in Chapter 7, in which Maria Elena Baynat Monreal analyzes the projected image of Spain in French Weblogs. Besides a very comprehensive introduction to the blog and the forum, the author accurately compares the acceleration of life in the $19^{\text {th }}$ century, based on the industrial revolution, the invention and promotion of the railway, the emergence of tourism and the appearance of travel literature, to the $21^{\text {st }}$ century, witness of the technological revolution, the invention of the Internet, the consolidation of tourism and the emergence of the latest evolution of travel writing: the weblog. Needless to say, the new features of Weblogs (dynamism, intertextuality, intentionality, among others) provide the reader with varied, multilayered and at times contradictory perspectives that were unthinkable in $19^{\text {th }}$ century travel writing. In this sense, travel blogs are presented as a way to explore both the projected image of Spain in France and the French bloggers' interests in Spain, among which the weather, accommodation, leisure time and gastronomy seem to be the most popular ones.

In Chapter, 8 Mercedes López-Santiago focuses on the study of tourists' comments in hotel e-guestbooks in French and Spanish. In terms of content, it is interesting to see that there is a limited range of activities in which the tourist is interested (i.e., the overall impression of the hotel, price, location, the rooms, the treatment received, the noise level at the hotel, the breakfast, the garage and the TV channels). Regarding formal aspects of the tourists' comments, Lopez-Santiago finds texts full of inaccurate expressions that characterise the genre. In fact, what seems to matter for the online user who decides to leave a comment is the communicative function, rather than correction or accuracy. The description of the French electronic comments selected for this study allowed the author to verify: 1) the influence of the comments in hotel management, as perceived in the responses to the customers' comments and 2) the influence of the Internet on their production, given the repetitive, stereotyped style.

Finally, in Chapter 9 Angela Sanchez-Lafuente Almela provides and in-depth and wellfounded analysis of the quality of the translation of various cybergenres in the COMET-VAL 
corpus into English. The author offers a comprehensive picture of the results from both a quantitative and qualitative analysis, in a way that the findings offer not only the frequency and distribution of the data, but also an interpretation of those. To do this, Sanchez-Lafuente Almela uses not only her own assessment of the translation but also that of four participants. The results show that spelling errors are certainly the most frequent inaccuracies in the texts. These are followed by occasional lexical inaccuracies, incorrect loans and lack of consistency in terms of translation procedures. As a result, it is worth noting that while comprehension is only affected slightly, stylistics, lexicon and grammar are clearly called into question.

In summary, this volume is successful in introducing and examining the relationship between tourism, discourse and travelling, what makes these nine chapters a major contribution to the study of tourism and online cybergenres from a linguistic perspective. The authors definitely show an impressive grasp of the tourism industry and the importance of online discoursive aspects. No doubt that this volume is useful not only for the analyst interested in discourse studies, terminology, pragmatics or translation studies, but also for the tourism professional who wants to make better business performance through information technology. 